\title{
DIFICULDADES ENFRENTADAS PELO EDUCADOR INFANTIL DO CAMPO EM TURMA MULTISSERIADA ${ }^{1}$
}

\author{
Andrêssa Glaucyara Silva Ramos, Universidade Federal de Campina Grande/UFCG, \\ Andressa.bsf_2012@hotmail.com \\ Emanuella Vieira Lopes, Universidade Federal de Campina Grande/UFCG, \\ Emmanuella1@gmail.com \\ Gabriela Cavalcanti Lucena, Universidade Federal de Campina Grande/UFCG, \\ Gabriela_cavalcante_lucena@hotmail.com \\ Zildene Francisca Pereira, Universidade Federal de Campina Grande/UFCG, \\ denafran@yahoo.com.br
}

\author{
RESUMO
}

Este artigo é parte de uma atividade avaliativa realizada na disciplina de Fundamentos e Metodologia da Educação Infantil II e teve como objetivos: analisar dificuldades que o professor de Educação Infantil do campo encontra no processo de ensino-aprendizagem, mediante as condições de trabalho a ele impostas; verificar como a história de vida influencia nas relações entre a profissão docente e a relação professor-aluno; analisar as principais dificuldades enfrentadas pelos professores e alunos nas classes de multisseriado na educação no campo. Fizemos uma breve reflexão acerca da educação campesina, suas especificidades e o descaso com este espaço. Realizamos uma entrevista semiestruturada com uma professora da rede Municipal da cidade de Bonito de Santa Fé/PB. De acordo com as reflexões suscitadas vimos que enquanto não repensarmos a educação campesina de forma que leve em consideração as diferentes histórias de vida, a cultura e a forma de viver das pessoas que lá residem ficará difícil assumirmos a postura de professores que querem despertar a criticidade dos alunos. Por fim, com este estudo, foi possível ressignificarmos nosso olhar para as salas multisseriadas e a responsabilidade do professor que atua no campo enquanto produtor de novos conhecimentos.

PALAVRAS-CHAVE: Educação no campo; Escolha da Profissão; Educação Infantil.

\begin{abstract}
This article is part of an evaluation activity carried out in the discipline of Fundamentals and Methodology of Early Childhood Education II and had the following objectives: to analyze difficulties that the teacher of Early Childhood Education finds in the teaching-learning process, through the conditions of work imposed on it ; To verify how life history influences the relationships between the teaching profession and the teacher-student relationship; To analyze the main difficulties faced by

\footnotetext{
${ }^{1} \mathrm{O}$ presente trabalho (não) contou com apoio financeiro de nenhuma natureza para sua realização.
} 
teachers and students in the multisite classes in rural education. We made a brief reflection about the peasant education, its specificities and the neglect with this space. We conducted a semi-structured interview with a teacher from the Municipal network of the city of Bonito de Santa Fé / PB. According to the reflections we have shown that until we rethink peasant education in a way that takes into account the different life histories, the culture and way of life of the people living there, it will be difficult to assume the position of teachers who want to arouse criticality from the students. Finally, with this study, it was possible to re-focus our eyes on the multi-series rooms and the responsibility of the teacher who works in the field as a producer of new knowledge.

KEY WORDS: Education in the field; Choice of Profession; Child education.

\section{RESUMEN}

Este artículo es parte de una actividad evaluadora realizada en la disciplina de Fundamentos y Metodología de la Educación Infantil II y tuvo como objetivos: analizar dificultades que el profesor de Educación Infantil del campo encuentra en el proceso de enseñanza-aprendizaje, mediante las condiciones de trabajo a él impuestas ; Como la historia de la vida influye en las relaciones entre la profesión docente y la relación profesor-alumno; Analizar las principales dificultades enfrentadas por los profesores y alumnos en las clases de multiseriado en la educación en el campo. Hemos hecho una breve reflexión acerca de la educación campesina, sus especificidades y el descuido con este espacio. Realizamos una entrevista semiestructurada con una profesora de la red Municipal de la ciudad de Bonito de Santa Fe / PB. De acuerdo con las reflexiones suscitadas vimos que mientras no repensar la educación campesina de forma que tenga en cuenta las diferentes historias de vida, la cultura y la forma de vivir de las personas que allí residen, será difícil asumir la postura de profesores que quieren despertar la criticidad De los alumnos. Finalmente, con este estudio, fue posible resignificar nuestra mirada hacia las salas multiserias y la responsabilidad del profesor que actúa en el campo como productor de nuevos conocimientos.

PALABRAS CLAVE: Educación en el campo; Elección de la profesión; Educación Infantil.

\section{INTRODUÇÃO}

Este artigo é parte de uma atividade avaliativa realizada na disciplina de Fundamentos e Metodologia da Educação Infantil II, no Curso de Pedagogia/UAE/CFP/UFCG², com uma carga horária de 90h/a, distribuídas entre estudos de referenciais teóricos acerca da Educação Infantil, atividades metodológicas e de pesquisa. Desse modo, realizamos uma entrevista semiestruturada com a professora Marta, nome fictício, que faz parte da rede Municipal de Educação na cidade de Bonito de Santa Fé/PB. A docente foi escolhida pelo seu

${ }^{2}$ UAE/Unidade Acadêmica de Educação, CFP/Centro de Formação de Professores, UFCG/Universidade Federal de Campina Grande, campus Cajazeiras/PB. 
envolvimento na educação do campo e, principalmente, por ser considerada uma excelente profissional, com uma experiência considerável no ensino infantil do nosso município.

No que diz respeito à formação dos profissionais para atuar na educação básica temos a Lei de Diretrizes e Bases da Educação (LDB, Lei 9.394/96) que prevê em seu Art. 62 que:

A formação de docentes para atuar na educação básica far-se-á em nível superior, em curso de licenciatura plena, admitida, como formação mínima para o exercício do magistério na educação infantil e nos cinco primeiros anos do ensino fundamental, oferecida em nível médio, na modalidade normal (BRASIL, 1996).

Dessa forma, percebemos que a professora entrevistada está apta para exercer o seu cargo. Sendo professora da Rede Municipal de Ensino, Graduada em Pedagogia e com PósGraduação em Psicopedagogia.

A ideia de escolhê-la para participar da nossa entrevista surgiu pelo fato dela se identificar com o trabalho da Educação Infantil e fazer da sua aula um campo fascinante de possibilidades, a partir da motivação dos alunos com relação a busca de novos conhecimentos. O descaso com a educação do campo é algo que tem se perpetuado no Brasil ao longo dos anos, pois sempre foi tratado com invisibilidade, mas a professora atua em sala multisseriada e tem procurado trabalhar novas estratégias de ensino que tem contribuído para uma educação de boa qualidade.

Realizamos, inicialmente, um apanhado histórico da educação no Brasil e vimos que esta desenvolveu-se de modo elitizado, onde apenas os mais abastados tinham acesso a uma educação de qualidade. Diante disso, vale ressaltar que durante alguns anos, a população do campo ainda não tinha consciência do poder da educação e, no seu imaginário, esta não se fazia importante, pois estes trabalhavam apenas no cultivo de alimentos. Esta falta de consciência para com a educação contribuiu para que o direito a escolarização continuasse a ser negado intencionalmente a população do campo, visto que a educação apenas lhes foi ofertada para conter o êxodo rural e aumentar a produção agrícola (CNE, MEC, 2001).

Atualmente, todo esse descaso em relação à educação campesina permanece, visto que muitas escolas, ainda, possuem profissionais sem a formação mínima exigida ou com formações aligeiradas, além de muitos possuírem uma sala única para o ensino multisseriado. De acordo com Lopes (2016, p. 122) 
A Educação do Campo, marcadamente, tem sido caracterizada pela invisibilidade e precarização em suas estruturas de oferta e de gestão nas Redes Municipais de Ensino. Suas dinâmicas de escolarização, a partir da sala de aula, na Educação Infantil e nos Anos Iniciais do Ensino Fundamental têm sido configuradas por um único professor assumindo múltiplas funções, por vezes, de merendeiro a educador/a, de secretário a gestor não-remunerado da educação escolar, além de lecionar para duas, três, quatro e até seis ou sete diferentes agrupamentos seriados diferentes ao mesmo tempo e em mesmo ambiente pedagógico.

Nesse sentido, observamos que o professor da escola do campo, ainda, se depara com muitas dificuldades: exercer diversas funções, trabalhar em sala multisseriada, ter cinco ou mais planejamentos, péssimas condições materiais de trabalho. Esta é a realidade da Educação do campo, aliada a desvalorização e não reconhecimento do professor, mas também dos próprios alunos.

Desse modo, para a realização desse trabalho elaboramos os seguintes objetivos: analisar dificuldades que o professor de Educação Infantil do campo encontra no processo de ensino-aprendizagem, mediante as condições de trabalho a ele impostas; verificar como a história de vida influencia nas relações entre a profissão docente e a relação professor-aluno; analisar as principais dificuldades enfrentadas pelos professores e alunos nas classes de multisseriado na educação no campo.

\section{MARGINALIZAÇÃO DA EDUCAÇÃO DO CAMPO INTEGRADA À DESVALORIZAÇÃO HISTÓRICA DA EDUCAÇÃO INFANTIL}

Desde a chegada dos jesuítas, vimos que a educação no Brasil tem sido oferecida as minorias de acordo com a cultura da classe dominante. Partindo dessa perspectiva, Bello (2001, p. 01) ressalta que,

[...] os portugueses trouxeram um padrão de educação próprio da Europa, o que não quer dizer que as populações que por aqui viviam já não possuíam características próprias de se fazer educação. E convém ressaltar que a educação que se praticava entre as populações indígenas não tinha as marcas repressivas do modelo educacional europeu. 
Foi assim que aconteceu com os índios e é assim que acontece com a Educação do Campo, visto que, atualmente, ainda há a tentativa de implantar no campo o mesmo modelo de educação que se tem nas escolas urbanas. Podemos afirmar que há, de fato, uma falta de respeito para com as especificidades e cultura dessa população. Conforme aponta a Resolução $n^{\circ} 2$, de 28 de abril de 2008, do Conselho Nacional de Educação quando diz que

A Educação do Campo compreende a Educação Básica em suas etapas de Educação Infantil, Ensino Fundamental, Ensino Médio e Educação Profissional Técnica de nível médio integrada com o Ensino Médio e destina-se ao atendimento às populações rurais em suas mais variadas formas de produção da vida - agricultores familiares, extrativistas, pescadores artesanais, ribeirinhos, assentados e acampados da Reforma Agrária, quilombolas, caiçaras, indígenas e outros (p.1).

Podemos destacar que devido à ausência de consciência da população do campo em relação ao valor da educação, esta permaneceu na invisibilidade por muito tempo, passando a despertar uma preocupação para um modelo educacional próprio somente no ano de 1997, quando foi realizado, em Brasília, o I Encontro Nacional de Educadores e Educadoras da Reforma Agrária (I ENERA) que, de acordo com Neto (2014, p. 161)

Este Encontro possibilitou que os debates sobre a educação nos assentamentos e acampamentos do MST ganhassem uma dimensão maior que a projetada inicialmente, construindo um grande movimento nacional "Por uma Educação do Campo".

Desse modo, o I ENERA representou não apenas a luta por terras dos integrantes do Movimento dos Trabalhadores Rurais Sem Terra (MST), mas também a preocupação destes em relação a elaboração de políticas públicas direcionadas a Educação do Campo. Pacheco; Silva; Pasuch (2014, p. 05-06) ressaltam que,

O movimento dos trabalhadores do campo fez nascer uma política nacional com o objetivo de fortalecer a educação nas áreas de reforma agrária de modo que os projetos educacionais pudessem ser desenvolvidos com foco nas especificidades do campo tendo em vista a promoção do desenvolvimento sustentável e a construção de educação vinculada ao mundo do trabalho, à cultura, ao modo de produção e a luta pela terra. 
Tais movimentos marcam o surgimento da consciência da população campesina em relação à educação e inicia a luta por um projeto educacional que esteja ligado ao seu modo de vida e a sua cultura. De acordo com o Art. 205 da Constituição Federal do Brasil de 1988

A educação, direito de todos e dever do Estado e da família, será promovida e incentivada com a colaboração da sociedade, visando ao pleno desenvolvimento da pessoa, seu preparo para o exercício da cidadania e sua qualificação para o trabalho.

Desse modo, vimos que, embora a Constituição não cite, diretamente, a Educação do Campo, esta é direito de todos os sujeitos, inclusive dos que compõem a população rural. A Lei $n^{\circ}$ 9.394/96 - Lei de Diretrizes e Bases da Educação Nacional (LDB), maior Lei que rege a educação brasileira, estabelece no seu Art. 28 que,

Na oferta da educação básica para a população rural, os sistemas de ensino proverão as adaptações necessárias à sua adequação, às peculiaridades da vida rural e de cada região, especialmente:

I- conteúdos curriculares e metodologia apropriada às reais necessidades e interesses dos alunos da zona rural;

II- organização escolar própria, incluindo a adequação do calendário escolar às fases do ciclo agrícola e às condições climáticas;

III- adequação à natureza do trabalho na zona rural.

Parágrafo único. $\mathrm{O}$ fechamento de escolas do campo, indígenas e quilombolas será precedido de manifestação do órgão normativo do respectivo sistema de ensino, que considerará a justificativa apresentada pela Secretaria de Educação, a análise do diagnóstico do impacto da ação e a manifestação da comunidade escolar (BRASIL, 1996).

No Artigo citado, a LDB preconiza que a educação ofertada à população rural deve estar em consonância com seu modo de vida, assim sendo, faz-se necessário um currículo que abranja tais especificidades. De acordo com Lopes (2016, p. 125),

[...] na luta nacional de educadoras e educadores do campo tem sido pautado que, a organização do trabalho pedagógico das escolas campesinas, partem e partirão dos modos e das práticas de vida e formação humana em espaços campesinos como referenciais metodológicos para se ensinar e aprender a partir do campo e de posturas e opções de vida a partir do campo ou para aquém ou além dele. 
O referido Artigo trata também do fechamento das escolas do campo, cujo principal argumento utilizado pelos órgãos responsáveis é que esta é uma solução para o problema das turmas multisseriadas, porém Lopes (2016, p. 124) esclarece que:

[...] a lógica do custo-benefício, pela qual o Ministério Público, por vezes, avalia os protocolos de fechamento das escolas do campo, da base da dinâmica gerencial do bem-público e do patrimônio público-estatal, junto aos executivos municipais, está dimensionada pela satisfação imediata do capital por si.

Reconhecido o impacto da referida ação sobre a comunidade escolar e sabendo que esta tem por finalidade apenas o acúmulo do capital, é fundante observar que o fechamento das escolas do campo infringe o direito da criança de ter acesso à escola pública e gratuita próxima de sua residência, como está estabelecido no Art. 53, Inciso V, da Lei $n^{\circ}$ 8.069, que dispõe sobre o Estatuto da Criança e do Adolescente (ECA). Sobre o referido Estatuto, Alves (2011, p. 09) complementa que:

O ECA reforça a cidadania da criança, apresentando mudanças na maneira de pensar a infância no país (da situação irregular para a proteção integral e do reconhecimento da criança e do adolescente como sujeito de direitos, pessoas em condição peculiar de desenvolvimento) [...].

Desse modo, o que se tinha até então era uma invisibilidade da criança que, consequentemente, era refletida no modelo educacional a ela ofertada. Sobre a questão, Amorim (2016, p. 161) ressalta que,

No que se refere aos profissionais que atuavam nas instituições, nas creches [...] não havia a exigência de professores para atuar com as crianças. Nas pré-escolas, por serem vinculadas às escolas, o trabalho era exercido por professoras. Entretanto, como a pré-escola se caracterizava como uma preparação para a escola, assumiam a função docente as professoras que atuavam na primeira fase do $1^{\circ}$ grau, ou seja, aquelas formadas em nível médio, modalidade Normal, que era o curso que até então formava professores para atuar nessa etapa.

Portanto, havia a predominância apenas de uma educação assistencialista e que não exigia uma formação do profissional da educação para trabalhar com as crianças. Diante dos 
fatos expostos, vimos que a atual e histórica desvalorização do profissional que atua na Educação Infantil é também associada a desvalorização da criança, que por muito tempo foi marginalizada.

A autora complementa informando que a Educação Infantil “[...] é uma área que se desenvolveu à margem do sistema educacional brasileiro" (AMORIM, 2016, p. 160). Em vista disso, a desvalorização da Educação Infantil do Campo é resultado não somente da desvalorização da própria população campesina, mas também da Educação Infantil de modo geral.

Outro fator que contribui para a desvalorização da educação campesina é o fato de que, por vezes, esta tem sido desenvolvida de acordo com o currículo da educação oferecida à população da zona urbana. Conforme aponta Souza; Santos (2007, p. 215) quando dizem que

O modelo de ensino dos cursos de formação de professores é pensado dentro da dinâmica das relações sociais, políticas e econômicas das cidades. Pouco ou nada nos cursos de formação se trabalha com a educação voltada para a especificidade do campo. Todos estes elementos contribuem para o distanciamento e desvalorização do ensino por parte da população do campo, estabelecendo assim a exclusão social.

São apontadas nessas reflexões a necessidade das instituições empreenderem uma formação de professores que se volte também para a Educação do Campo. Em vista disso, faz-se necessário para população campesina uma educação que se desenvolva numa perspectiva libertadora, contrária ao que Freire (2015) chama de educação "bancária", que apenas deposita o conhecimento no educando, visto que, para o autor, o que importa é aprender a pensar, pois considera que aprender não é acumular conhecimentos. Isto posto, o autor atribui à educação a função social de proporcionar o empoderamento do indivíduo.

Na compreensão de Freire (1967, p. 37) a “[...] conscientização é uma das fundamentais tarefas de uma educação realmente libertadora e por isto respeitadora do homem como pessoa." Em vista disso, há na oferta da Educação do Campo a necessidade de formar educandos que conheçam seus direitos, que façam-se ser vistos pela sociedade como indivíduos realmente capazes de agir e interagir nesta, tornando-se sujeitos da própria história, fazendo-se conhecedores das Leis e mudando esse histórico de invisibilidade que por muito tempo lhes foi atribuído. 


\section{A ESCOLHA DA PROFISSÃO DOCENTE E SEUS EFEITOS}

Muito tem se falado sobre a educação e sobre as diversas formas de ensinar, desde o tradicionalismo, muito presente na educação e também sobre o movimento dos Pioneiros da Escola Nova. Sabemos que o tradicionalismo contempla a figura do professor como 'centro' no processo de ensino-aprendizagem e que os seus alunos eram meramente receptores como nos traz Paulo Freire quando se refere a uma educação "bancária". Segundo Antunes (2007, p.15): "Era assim que se pensava "aula" há trinta anos. O professor era o centro do processo de ensino e o aluno apenas um receptor de saberes que, aula a aula, ia acumulando".

Observamos que a fala da nossa entrevistada condiz com o pensamento do autor, quanto este trata dos castigos que eram imposto aos alunos. Podemos acompanhar no relato.

[...] a minha primeira professora foi a minha mãe, ela era professora, então assim, dentro da realidade, que eu sou de 1972 [...] eu fui muito bem alfabetizada dentro daquela realidade, claro que era mais tradicional né? Eu sou da época da palmatória, minha mãe não usava a palmatória, mas, quando eu comecei... isso o meu ensino infantil, como diz a carta de $\mathrm{ABC}$ foi com a minha mãe então quando eu fui para a cartilha na época ai já foi na escola propriamente dita né?" (Professora Marta)

Podemos então observar que o modelo tradicional de ensino, não se preocupava em entender os seus alunos e sim de depositar os conteúdos nestes, para que eles apenas aprendessem o que era imposto, não se preocupavam em visualizar as experiências de cada um, e que quando seus alunos não absorviam aquilo imposto pelos professores, ou não correspondiam aquilo que era "transferido" muitas vezes recebiam castigos, como traz a Professora Marta quando diz: “[...] Parabenizo e defendo o tradicionalismo sim, porque é o resultado do meu hoje. [...] como é que tu ensina a ler sem a criança ler, praticando, como é que tu ensinas a criança a escrever sem a criança praticar a escrita [...]".

Sabemos que na história educacional do Brasil, muita coisa já foi mudada, porém podemos observar que o modelo tradicional ainda é presente, através do repasse de conteúdos, muitos vezes decorados. Desse modo, ao observarmos a fala da professora vimos que ela ao exercer o processo de ensino-aprendizagem, não utiliza o modelo tradicional como uma educação meramente bancária, mas busca fazer a tão discutida relação teoria-prática em sala de aula, favorecendo novos conhecimentos aos alunos. 
A professora tem a preocupação de estimular as habilidades dos seus alunos quando se refere a "fazer um coquetel de metodologias", pois "Quem ensina aprende ao ensinar e quem aprende ensina ao aprender" (Freire, 2015, p. 25).

A Educação no Campo por muito tempo foi uma educação "precária" e que por muitos anos não se era dada a sua devida atenção. Nessa perspectiva é que a educação campesina foi dada apenas para o aumento da produção agrícola. Podemos identificar que a professora entrevistada, ao citar que "crianças que não teve esse aprendizado" aprendizado este que seria papel da família como pedir, por favor, as palavras mágicas como desculpa, com licença, e obrigada, aprender a respeitar os seus professores e entre tantas outras que hoje o educador é quem necessita fazer os dois papéis. Mesmo fazendo os dois papéis, o educador do campo, muitas vezes, é valorizado pela própria comunidade, e é considerado uma pessoa importante. Muitos professores que trabalham no campo se sentem realizados mesmo com todos os desafios impostos. Assim, podemos enfatizar que n "[...] zona rural a coisa é diferente. Você é muito importante para os alunos e até para a comunidade, você entendeu como? Você é uma pessoa, você é importante, eles gostam de você, você tem valor [...]” (JESUS, 2000. p. 34).

Ao tratarmos da profissão docente, logo nos remetemos à história dos profissionais da educação, de como estes se inseriram nesta trajetória, se foi por escolha própria ou por falta de opção. Por muito tempo sabemos que a profissão de "professora" era destinada apenas para mulheres, ao se referir que estas tinham mais cuidado, mais afeto e um jeito único de cuidar das crianças. Além do que a profissão, ainda, era repassada de geração. O "ser professora" não aparece nas vidas das professoras de forma naturalizada" (JESUS, 2000 p. 24). Ou seja, o ser professora não é uma coisa sua, que você nasce com ela, já que muitas pessoas acreditam que para esta profissão é preciso ter um 'dom’ ou uma 'vocação'. A professora diz: “[...] eu sou eternamente apaixonada por escola, Porque como eu sou filha de professora, eu sou neta de professora, então eu trago essa questão de escola no sangue (Professora Marta).

Falar de escola, escolha da profissão, faz-nos pensar na questão da afetividade, pois nos vem à mente o abraçar e beijar, porém a afetividade não se enquadra basicamente nesses padrões, pois a "Afetividade refere-se à capacidade, à disposição do ser humano de ser afetado pelo mundo externo/interno por sensações ligadas a tonalidades agradáveis ou desagradáveis" (MAHONEY, ALMEIDA. 2005, p. 19). 
Desse modo, a afetividade no contexto escolar precisa estar presente, pois de acordo com Freire (2015, p.138) “[...] preciso descartar como falsa a separação radical entre seriedade docente e afetividade. [...] O que não posso obviamente é permitir que minha afetividade interfira no cumprimento ético de meu dever de professor, no exercício de minha autoridade." A professora relata uma experiência quando diz:

[...] eu tive um professor de matemática que pela misericórdia (risos) ele era o carrasco, Car-rras-co gente, sabe aquele professor que quando você diz assim professor de matemática, pronto, você congela, trava, nem escreve direito, só pra sobreviver, somente. [...] muito rígido, muito durão [...] O que deixou mais papão ainda (risos) e assim eu me peguei um trauma, eu travava gente, certo? Por causa do medo dele né? (Professora Marta)

Nessa perspectiva, ao analisarmos a fala da professora Marta percebemos que o professor a quem esta se refere era um professor que se utilizava do poder para amedrontar as crianças, afetando-os de forma negativa, onde estes se sentiam incapazes de aprender. A professora Marta fala de uma experiência vivida em casa que é satisfatória quando relata: “[...] hoje eu vivo uma experiência bem interessante que a minha filha tem um professor de matemática e o meu filho que eles defendem, eles são apaixonados chegar a hora da aula de matemática, por quê? Porque o professor [...] sempre apronta uma brincadeira, uma coisa, né?

É possível acrescentarmos que o professor é considerado amigo dos alunos, desperta a vontade de permanecerem na escola e aprenderem matemática de forma diferenciada. De acordo com Freire ( 2015 , p.70) "Há uma relação entre a alegria necessária à atividade educativa e a esperança. A esperança de que o professor e alunos juntos podemos aprender, ensinar, inquietar-nos, produzir e juntos igualmente resistir aos obstáculos a nossa alegria".

Podemos afirmar que existem diferentes modelos de professores que nos afetam de forma positiva ou negativa e mediante essa situação, se torna necessário que os educadores revejam as suas experiências e o modo que estes veem seus alunos, pois ao influenciar de modo negativo ou positivo a vida do aluno deixam marcas não serão esquecidas. Dessa forma, "Esta abertura ao querer bem não significa, na verdade, que, porque professor, me obrigo a querer bem a todos os alunos de maneira igual. Significa, de fato, que a afetividade não me assusta, que não tenho medo de expressá-la" (FREIRE, 2015, p. 138). 
Vimos que a relação professor-aluno, bem como o modo que este exerce sua prática docente tem ligação direta como o que levou a escolher a profissão, se foi uma escolha feita por vontade ou por falta de opção. Tendo em vista que a profissão docente possui uma baixa remuneração e, muitas vezes, é alvo de desvalorização.

O ensino na sala multisseriada, embora muito criticado, contribui para que o educando desenvolva sua capacidade de conviver com diferentes ideias e culturas, convivendo com crianças de faixa etárias distintas, compreendendo que cada indivíduo possui certas especificidades e que estas devem ser respeitadas. Portanto, o ensino multisseriado contribui para a formação de um educando altruísta, capaz de respeitar e dedicar-se aos outros. Assim, de acordo com Souza; Santos (2007, p. 213)

As escolas multisseriadas encontram grandes dificuldades de funcionamento no sistema educacional brasileiro. [...] elas são marginalizadas pela sociedade como escolas com o ensino deficiente. Nesta perspectiva, tenta-se legitimar a idéia de que para o homem do campo não são necessárias as letras, apenas a enxada. Por outro lado, as escolas multisseriadas podem ser compreendidas como possibilidade de desenvolver um processo educativo diferente, em que alunos de diversas faixas etárias e experiências podem participar/criar formas coletivas de apropriação do conhecimento. É preciso repensar a organização secular da instituição escola, os tempos e espaços fragmentados.

Podemos então observar que, o ensino na sala multisseriada, para muitos professores é um grande desafio, em que, muitas vezes, não se acham capazes de desenvolver suas atividades e seus planejamentos, tendo em vista que essa especificidade de ensino inclui várias séries em uma classe só. Ao analisarmos as falas da professora Marta, identificamos que está sente-se realizada ao trabalhar em uma escola de classe multisseriada, tendo em vista que encontrou muitos desafios para exercer essa modalidade de ensino. Assim a professora Marta relata: “[...] não vou dizer a vocês que é bem facinho não, mas eu digo a vocês que é possível [...] porque você tem que colocar amor, você tem que querer a coisa, mas que dá certo dá”.

Ao se referir que é preciso querer para poder fazer acontecer, podemos citar um fato muito importante para o ensino-aprendizagem, que é o planejamento. Planejamento esse que precisa ser flexível e de acordo com cada série que este esteja ensinando, é preciso que este se adapte a realidade em que o educador e os educandos estejam inseridos, pois assim como nos recorda Freire $(2015$, p. 94) “[...] uma de minhas preocupações centrais deva ser a de procurar 
aproximação cada vez maior entre o que digo e o que faço, entre o que pareço ser e o que realmente estou sendo".

Mediante essa afirmação que podemos analisar, que se torna realmente necessário que aquilo que eu planejo seja executado, para fim de desenvolver a aprendizagem do aluno e obter essa aproximação entre o que planejo e o que de fato se desenvolve. Para a professora Marta, "Também aquele planejamento sou contra, desculpa aí as colegas e colegas professores, só planejar pra mandar o papel bonito, não funciona. Eu sou assim, eu acho que você tem que planejar dentro da realidade e que seja possível executar".

As aulas não devem abordar apenas o que está estabelecido no livro didático, o saber sistematizado, mas o conhecimento apresentado aos alunos deve também contribuir para que estes exerçam sua criticidade. Dessa forma, de acordo com Freire $(2015$, p. 53) “[...] minha presença no mundo não é a de quem a ele se adapta mas a de quem nele se insere. É a posição de quem luta para não ser apenas objeto, mas sujeito também da história”.

Desse modo, para que o aluno seja sujeito da história, é necessário uma educação baseada na criticidade dos fatos vivenciados, de modo que este tenha a oportunidade de conhecer seus direitos e deveres e reivindicá-los quando preciso for e que sua inserção no mundo seja de forma ativa.

\section{CONSIDERAÇÕES}

A Educação do Campo ganhou visibilidade a partir de movimentos iniciados pelos próprios trabalhadores campesinos. Desse modo, foram elaboradas políticas públicas para a valorização e investimento nessa área. Porém, diante da análise das citadas Leis, Resoluções e Decretos, ficam visíveis que muitas exigências estabelecidas em tais documentos não estão sendo cumpridas nas instituições de ensino, pois o desrespeito a população campesina permanece, atrelado a pouca valorização do ensino destinado às crianças, resultando assim na desvalorização da Educação Infantil do Campo que é contemplada por Leis como: Constituição Federal/1988, ECA/1990, LDB/1996, mas que nem sempre são valorizadas pela sociedade.

Observamos que muitos professores não querem trabalhar com turmas multisseriadas pelo fato que, entendem esta como uma 'dificuldade' a ser trilhada e trazendo como base as reflexões da Professora Marta, entendemos que para a ela o multisseriado não é só um 
desafio, mas uma forma de fazer com que a Educação do Campo melhore a cada dia, fazendo aquilo que é possível diante das necessidades existentes. Desse modo, ressaltamos a importância de um planejamento que seja capaz de ser realizado, levando em consideração a localidade. Sendo assim, flexível, para atender as diversas séries, modalidades, especificidades e dificuldades que possam ser apresentadas pelos alunos.

Podemos concluir afirmando que a Educação do Campo, mesmo sendo desvalorizada por alguns profissionais, não deixa de ser uma educação em que se deve ressaltar a importância desta para a sociedade. Percebemos, mediante os estudos realizados e o posicionamento da professora Marta, a necessidade de maiores discussões acerca das salas multisseriadas no campo enquanto espaço propício a construção de novos saberes e de ressignificação do espaço escolar.

\section{REFERÊNCIAS}

ALMEIDA, Laurinda Ramalho de. MAHONEY, Abigail Alvarenga. Afetividade e processo de ensino-aprendizagem: contribuições de Henri Wallon. Psic. da Ed., São Paulo, 20, $1^{\circ}$ sem. de 2005, pp.11-30.

ALVES, Bruna Molisani Ferreira. Infâncias e educação infantil: aspectos históricos, legais e pedagógicos. Revista Aleph, infâncias. ISSN 1807-6211. Ano V. Nº 16. Novembro, 2011.

ANTUNES, Celso. Professores e professauros: reflexões sobre a aula e práticas pedagógicas diversas. Petrópolis, RJ: Vozes, 2007.

AMORIM, Ana Luiza Nogueira de. Formação de professores de educação infantil no alto sertão paraibano. In: LOPES, Wiama de Jesus Freitas. SANTIAGO, Stella Márcia de Morais (orgs). Formação de professores e identidades docentes em questão: o que nos ensina os 30 anos de pedagogia no alto sertão paraibano. Fortaleza : Imprece, 2016.

BELLO, José Luiz de Paiva. Educação no Brasil: A História das rupturas. Pedagogia em Foco, Rio de Janeiro 2001. Disponível em: <http://www.pedagogiaemfoco.pro.br/heb14.htm>. Acesso em: 02 de julho de 2009.

BRASIL. Constituição da República Federativa do Brasil. Brasília, 1988. Disponível em < http://www.planalto.gov.br/ccivil_03/constituicao/constituicaocompilado.htm>. Acesso em 25 de abril de 2017. 
BRASIL. Ministério da Educação. RESOLUÇÃO No 2, DE 28 DE ABRIL DE 2008(*). Conselho Nacional de Educação, Câmara de Educação Básica. Disponível em $<$ http://portal.mec.gov.br/secad/arquivos/pdf/resolucao0208.pdf $>$. Acesso em 25 de abril de 2017.

BRASIL. Presidência da República. Casa Civil. Lei ${ }^{\circ}$ 8.069/1990. Estatuto da criança e do adolescente. Brasília, DF: Diário Oficial da União, 16 jul 1990. Disponível em: <http://www.planalto.gov.br/ccivil_03/Leis/L8069.html> Acesso em: 11/09/2016.

BRASIL. Presidência da República. Casa Civil. Lei n 9.394/1996. Lei de Diretrizes e Bases da Educação Nacional. Brasília, DF: Diário Oficial 23 dez 1996. Disponível em: <http://www.planalto.gov.br/ccivil_03/Leis/L9394.htm> Acesso em: 11/09/2016.

BRASIL. CONSELHO NACIONAL DE EDUCAÇÃO. Diretrizes complementares, normas e princípios para o desenvolvimento de políticas públicas de atendimento da Educação Básica do Campo. Resolução Complementar CNE/CEB No 2, de 2008. Disponível em: <http://portal.mec.gov.br/secad/arquivos/pdf/resolucao0208.pdf >. Acesso em 25 de abril de 2017.

BRASIL. Conselho Nacional de Educação. Diretrizes Operacionais para a Educação Básica das Escolas do Campo. Parecer CNE/CEB no 36 de 2001. Disponível em: $<$ http://pronacampo.mec.gov.br/imagens/pdf/mn_parecer_36_de_04_de_dezembro_de_2001. pdf $>$. Acesso em 25 de agosto de 2017.

FREIRE, Paulo. Educação como prática da liberdade. Rio de Janeiro: Paz e terra, 1967.

Pedagogia da autonomia: saberes necessários à prática educativa. $51^{\text {a }}$ ed - Rio de Janeiro: Paz e Terra, 2015.

JESUS, Regina de Fátima de. Sobre alguns caminhos trilhados... ou mares navegados... Hoje sou professora. In VASCONCELOS Geni Amélia Nader. Como me fiz professora. [ilustrações: Ricardo Coulart]. Rio de Janeiro: DP\&A, 2000.

LOPES, Wiama de Jesus Freitas. A educação do campo e seus desafios na formação de professores: o que nos aponta os 35 anos da pedagogia no CFP acerca da questão. In: LOPES, Wiama de Jesus Freitas. SANTIAGO, Stella Márcia de Morais (orgs). Formação de professores e identidades docentes em questão: o que nos ensina os 30 anos de pedagogia no alto sertão paraibano. Fortaleza : Imprece, 2016.

NETO, Adolfo Oliveira. A luta pela educação no campo: uma conquista em processo. Revista GeoAmazônia - ISSN: 2358-1778 (on line) 1980-7759(impresso), Belém, n. 2, v. 2, p. $159 \quad$ - 172, jul./dez. 2014. Disponível em: < http://www.academia.edu/11020475/A_LUTA_PELA_EDUCA\%C3\%87\%C3\%830_DO_C AMPO_UMA_CONQUISTA_EM_PROCESSO>. Acesso em 25 de abril de 2017. 
PACHECO, Adriana. SILVA, Cléria Paula Franco da. PASUCH, Jaqueline. A educação infantil do campo na perspectiva da valorização da criança enquanto sujeito do campo. 2014. Disponível em: < http://www.grupeci.fe.ufg.br/up/693/o/TR68.pdf> $>$. Acesso em 25 de abril de 2017.

SOUZA, Maria Antônia. SANTOS, Fernando Henrique Tisque dos. Educação do campo: prática do professor em classe multisseriada. Diálogo Educ. Curitiba, v.7, 211-227, set./dez.2007. Disponível em: < http://www.labeduc.fe.usp.br/wp-content/uploads/FernandoHenrique-1dialogo-1584.pdf $>$ Acesso em 25 de abril de 2017. 